\title{
Highly absorptive curcumin reduces serum atherosclerotic low-density lipoprotein levels in patients with mild COPD
}

This article was published in the following Dove Press journal:

International Journal of COPD

26 August 2016

Number of times this article has been viewed

\author{
Masafumi Funamoto 1,2 \\ Yoichi Sunagawa ${ }^{1-3}$ \\ Yasufumi Katanasaka ${ }^{1-3}$ \\ Yusuke Miyazaki ${ }^{1,2}$ \\ Atsushi Imaizumi ${ }^{4}$ \\ Hideaki Kakeya ${ }^{5}$ \\ Hajime Yamakage ${ }^{2}$ \\ Noriko Satoh-Asahara ${ }^{2}$ \\ Maki Komiyama ${ }^{2}$ \\ Hiromichi Wada ${ }^{2}$ \\ Koji Hasegawa ${ }^{2}$ \\ Tatsuya Morimotol-3 \\ 'Division of Molecular Medicine, \\ School of Pharmaceutical Sciences, \\ University of Shizuoka, Shizuoka, \\ ${ }^{2}$ Clinical Research Institute, National \\ Hospital Organization Kyoto \\ Medical Center, Kyoto, ${ }^{3}$ Shizuoka \\ General Hospital, Shizuoka, \\ ${ }^{4}$ Theravalues Corporation, Kioicho, \\ Tokyo, ${ }^{5}$ Department of System \\ Chemotherapy and Molecular \\ Sciences, Division of Bioinformatics \\ and Chemical Genomics, Graduate \\ School of Pharmaceutical Sciences, \\ Kyoto University, Kyoto, Japan
}

Correspondence: Tatsuya Morimoto Division of Molecular Medicine, School of Pharmaceutical Sciences, University of Shizuoka, 52-I Yada, Suruga-ku, Shizuoka 422-8526, Japan

Tel +8I 542645763

Fax +8I 542645744

Email morimoto@u-shizuoka-ken.ac.jp
Purpose: COPD is mainly caused by tobacco smoking and is associated with a high frequency of coronary artery disease. There is growing recognition that the inflammation in COPD is not only confined to the lungs but also involves the systemic circulation and can impact nonpulmonary organs, including blood vessels. $\alpha 1$-antitrypsin-low-density lipoprotein (AT-LDL) complex is an oxidatively modified LDL that accelerates atherosclerosis. Curcumin, one of the bestinvestigated natural products, is a powerful antioxidant. However, the effects of curcumin on AT-LDL remain unknown. We hypothesized that Theracurmin ${ }^{\circledR}$, a highly absorptive curcumin with improved bioavailability using a drug delivery system, ameliorates the inflammatory status in subjects with mild COPD.

Patients and methods: This is a randomized, double-blind, parallel-group study. Subjects with stages I-II COPD according to the Japanese Respiratory Society criteria were randomly assigned to receive $90 \mathrm{mg}$ Theracurmin ${ }^{\circledR}$ or placebo twice a day for 24 weeks, and changes in inflammatory parameters were evaluated.

Results: There were no differences between the Theracurmin ${ }^{\circledR}$ and placebo groups in terms of age, male/female ratio, or body mass index in 39 evaluable subjects. The percent changes in blood pressure and hemoglobin A1c and LDL-cholesterol, triglyceride, or high-density lipoprotein-cholesterol levels after treatment were similar for the two groups. However, the percent change in the AT-LDL level was significantly $(P=0.020)$ lower in the Theracurmin ${ }^{\circledR}$ group compared with the placebo group.

Conclusion: Theracurmin ${ }^{\circledR}$ reduced levels of atherosclerotic AT-LDL, which may lead to the prevention of future cardiovascular events in mild COPD subjects.

Keywords: curcumin, AT-LDL, COPD, atherosclerosis

\section{Introduction}

COPD is a lifestyle-related disease of the lungs that is primarily caused by regular smoking. ${ }^{1}$ It is an inflammatory disease associated with damage to the alveolar septa and increased levels of inflammatory mediators, such as C-reactive protein (CRP), interleukin-6, interleukin-1 $\beta$, and tumor necrosis factor- $\alpha$ (TNF- $\alpha$ ) in the lung periphery. ${ }^{2}$ This local inflammation in the lungs spills into the systemic circulation, where it causes systemic inflammation. ${ }^{3}$ Research has suggested that the systemic effects of COPD can also cause comorbidities, such as cardiovascular diseases..$^{3,4}$ Thus, COPD has attracted attention as a systemic disease..$^{3,5}$

The systemic inflammation of COPD is suggested to be involved in the pathogenesis of ischemic heart diseases and arteriosclerosis. ${ }^{6}$ Several reports demonstrated that athosclerotic plaques in COPD patients show a low-grade inflammation similar to 
that in the peripheral lungs. ${ }^{3,78}$ Actually, the cause of death for $20 \%-30 \%$ of patients with COPD is cardiovascular disease, and death due to cardiovascular disease is highly evident in patients with mild or moderate COPD. ${ }^{9,10}$ However, the precise mechanism of arteriosclerotic cardiovascular diseases and their effective preventive strategy in patients with COPD are still unknown. COPD is also considered as an independent risk factor for ischemic disorders. Thus, it is associated with the pathology of cardiovascular diseases and is a factor that governs the severity of cardiovascular disease. Research has also suggested that COPD is related to prognosis. Long-acting inhaled anticholinergics, such as tiotropium, are used in curing COPD, and the UPLIFT trial examined the usefulness of these medications. The results of this trial and a subanalysis indicated that patients using tiotropium had improved respiratory function and a decreased risk of cardiovascular complications, such as myocardial infarction. ${ }^{11,12}$ In other words, research has suggested that COPD is a therapeutic target for the improvement of prognosis in patients with cardiovascular diseases.

$\mathrm{CRP}$ is the most extensively studied marker of systemic inflammation. Various epidemiological studies have indicated that CRP is a factor that predicts cardiovascular events, such as myocardial infarction. ${ }^{13-15}$ In addition, a study that examined systemic inflammation in patients with COPD reported that these patients had increased levels of inflammatory markers, such as circulating neutrophils, fibrinogen, TNF- $\alpha$, and CRP. ${ }^{5}$

$\alpha 1$-Antitrypsin-low-density lipoprotein (AT-LDL) complex is a recently identified oxidized LDL. AT-LDL is found in human serum and at sites of atherosclerotic lesions, and the levels of AT-LDL in the blood indicate the activity of foam cells in atherosclerotic lesions. ${ }^{16,17}$ Serum amyloid A (SAA) bonds to high-density lipoprotein. When reactive oxygen species from inflammatory cells are activated by inflammation in blood vessels, they bond SAA to LDL to form a complex known as SAA-LDL. SAA-LDL is a potential marker that can be used to predict and thus prevent the occurrence of coronary events. ${ }^{18}$

Curcumin is a polyphenol naturally found in turmeric and has anti-inflammatory and antioxidant activities. Turmeric has been used as a remedy in traditional Indian and Chinese medicine for over 6,000 years. It is also extensively used as a spice, flavoring agent, food preservative, and food color. Curcumin has a number of biological activities, such as anti-inflammatory and anticancer actions. ${ }^{19,20}$ Over the past few years, some useful effects of curcumin in treating various disorders have been identified. ${ }^{19-21}$ We previously reported the use of curcumin in two rat models of chronic heart failure following hypertensive heart disease and myocardial infarction. ${ }^{22}$ Curcumin was effective at inhibiting the progression of heart failure.

Because of its various biological activities, curcumin may be used clinically. However, the drawbacks of curcumin are a very limited absorbability when ingested and a poor bioavailability. Thus, we used a drug delivery system to develop a highly absorbable curcumin preparation (Theracurmin ${ }^{\circledR}$; Theravalues Corporation, Kioi, Tokyo, Japan) to increase its absorption in the intestinal tract. Natural curcumin forms extremely large granules in an aqueous solution, but Theracurmin ${ }^{\circledR}$ is a preparation that features coated, extremely fine microparticles of curcumin. With such a drug delivery system, curcumin is consistently dispersed in an aqueous solution, thus improving its absorption by the intestinal tract. ${ }^{23}$

Curcumin is reported to have anti-inflammatory activity as it inhibits nuclear factor- $\mathrm{KB}(\mathrm{NF}-\mathrm{\kappa B})$ as well as antioxidant activity as it eliminates reactive oxygen species. ${ }^{24}$ Thus, curcumin may inhibit inflammation and oxidative stress, both implicated in increasing the risk of cardiovascular diseases. Accordingly, our objective was to evaluate the efficacy of Theracurmin ${ }^{\circledR}$ in patients with mild COPD by examining its effects on oxidative stress markers and inflammatory markers.

\section{Patients and methods Subjects}

The purpose of this trial was fully explained to potential subjects verbally and in writing. Once potential subjects provided written informed consent, they were allowed to participate in this trial. The subjects were men or women (age, 20-85 years) who met the following criteria: 1 ) patients with COPD at stage 0 , I, or II according to the definition by the Japanese Respiratory Society and 2) patients who have never smoked at least for the past 4 months. We enrolled patients with COPD (including those being treated for the condition) who were classified as having stage I (mild) or stage II (moderate) COPD based on the classification system of the Japanese Respiratory Society. During observation, the quantity and frequency of the dose remained unchanged for the patients being treated for COPD, and the patients had stable disease with no acute exacerbation.

\section{Trial protocol}

This trial was reviewed and approved by the ethics committee of the Kyoto Medical Center. The trial was registered with UMIN (UMIN: R000010713) before it began. Based on the philosophy of the ethical principles originating in the 
Declaration of Helsinki, this trial protected the rights and welfare of subjects. To ensure the scientific nature and reliability of this trial and to ensure safety, this trial was conducted in accordance with the principles of good clinical practice and strictly adhered to the Ministry of Health, Labor, and Welfare's ethical guidelines for clinical research.

We conducted this double-blind, parallel-group, randomized trial from October 2012 to September 2014. Once the written informed consent was obtained, the subjects were randomly assigned to one of the two groups (the Theracurmin ${ }^{\text {B }}$ [Theravalues Corporation, Kioi, Tokyo, Japan] group or the placebo group). The subjects took three capsules of Thera$\operatorname{curmin}^{\circledR}$ (Theracurmin ${ }^{\circledR}$ is sold as a health supplement) or a placebo ( $90 \mathrm{mg}$ in total, $30 \mathrm{mg}$ per capsule) twice a day (after breakfast and dinner, total dose: $180 \mathrm{mg}$ ). Theracurmin ${ }^{\circledR}$ or a placebo was taken over a period of 24 hours. The primary end points were oxidative stress markers and inflammatory markers (CRP, SAA-LDL, and AT-LDL). The duration of the trial was from October 2012 to September 2014.

\section{Statistical analysis}

Parametric data, ie, continuous data, were expressed as mean \pm standard deviation. As part of statistical analysis, a Mann-Whitney $U$-test was used to compare continuous data between the two groups. For analysis of three or more matched groups, Friedman test was performed followed by the Wilcoxon signed-rank test with Bonferroni correction as a post hoc test. All analyses were done using SPSS Version 22.0 for Windows (IBM Corporation, Armonk, NY, USA), with $P<0.05$ indicating statistical significance.

\section{Results}

Of the 48 subjects enrolled, four dropped out: one because of soft stool (placebo group), one because of gastrointestinal bleeding (Theracurmin ${ }^{\circledR}$ group), one because of muscle aches (placebo group), and one because of a rash on the back (placebo group). Five subjects withdrew their consent (four in the placebo group and one in the Theracurmin ${ }^{\circledR}$ group) because they would not like to take the trial medication of their own free will despite a lack of symptoms, leaving 39 subjects in the final analysis. The placebo group comprised 17 subjects ( 15 men and two women), and the Theracurmin ${ }^{\circledR}$ group comprised 22 subjects (19 men and three women).

The baseline characteristics of the subjects in both groups are listed in Table 1. There were no significant differences between the two groups in terms of sex, age, systolic blood pressure, diastolic blood pressure, glycated hemoglobin, blood sugar, triglyceride, LDL-cholesterol, high-density lipoproteincholesterol, uric acid, $\gamma$-glutamyl transpeptidase, creatinine,
Table I Baseline characteristics of the participants in each group

\begin{tabular}{|c|c|c|c|c|c|}
\hline Parameters & $n$ & Placebo & $n$ & Theracurmin $^{\circledR}$ & $P$-value \\
\hline $\operatorname{Sex}(M / F)$ & 17 & $15 / 2$ & 22 & $19 / 3$ & $>0.999$ \\
\hline Age, years & 17 & $69.9 \pm 6.3$ & 22 & $69.6 \pm 6.6$ & 0.868 \\
\hline BMI, kg/m² & 17 & $24.4 \pm 4.3$ & 22 & $22.1 \pm 2.6$ & 0.046 \\
\hline $\mathrm{SBP}, \mathrm{mmHg}$ & 17 & $127.7 \pm 19.0$ & 22 & $127.6 \pm 16.9$ & 0.990 \\
\hline $\mathrm{DBP}, \mathrm{mmHg}$ & 17 & $70.5 \pm 11.7$ & 22 & $70.7 \pm 11.6$ & 0.955 \\
\hline $\mathrm{HbAlc}, \%$ & 17 & $5.3 \pm 0.5$ & 22 & $5.4 \pm 0.4$ & 0.859 \\
\hline $\mathrm{BS}, \mathrm{mg} / \mathrm{dL}$ & 16 & $98.6 \pm 15.9$ & 21 & $102.8 \pm 23.1$ & 0.544 \\
\hline $\mathrm{TG}, \mathrm{mg} / \mathrm{dL}$ & 17 & $160.1 \pm 86.8$ & 22 & $\mid 46.3 \pm 70.2$ & 0.585 \\
\hline LDL-C, mg/dL & 17 & $104.5 \pm 21.6$ & 22 & $106.8 \pm 27.6$ & 0.784 \\
\hline $\mathrm{HDL}-\mathrm{C}, \mathrm{mg} / \mathrm{dL}$ & 17 & $60.1 \pm 9.6$ & 22 & $62.1 \pm 17.2$ & 0.658 \\
\hline $\mathrm{UA}, \mathrm{mg} / \mathrm{dL}$ & 16 & $6.2 \pm 1.3$ & 22 & $6.6 \pm 1.2$ & 0.326 \\
\hline$\gamma$-GTP, IU/L & 17 & $39.8 \pm 31.2$ & 22 & $52.3 \pm 52.7$ & 0.392 \\
\hline Cre, mg/dL & 16 & $1.0 \pm 0.3$ & 22 & $0.9 \pm 0.3$ & 0.512 \\
\hline CRP, mg/dL & 16 & $0.2 \pm 0.2$ & 22 & $0.3 \pm 0.8$ & 0.759 \\
\hline SAA-LDL, $\mu g / m L$ & 16 & $8.9 \pm 7.8$ & 21 & $14.0 \pm 36.5$ & 0.587 \\
\hline AT-LDL, $\mu g / m L$ & 16 & $1.2 \pm 0.2$ & 21 & $1.4 \pm 0.3$ & 0.037 \\
\hline $\mathrm{FEV}_{1} \%$ & 17 & $64.7 \pm 7.8$ & 22 & $61.9 \pm 8.3$ & 0.305 \\
\hline
\end{tabular}

Note: Data are presented as mean $\pm S D$, median (interquartile range), or number of patients.

Abbreviations: M/F, male/female; BMI, body mass index; SBP, systolic blood pressure; DBP, diastolic blood pressure; HbAlc, hemoglobin Alc; BS, blood sugar; TG, triglyceride; LDL-C, low-density lipoprotein-cholesterol; HDL-C, highdensity lipoprotein-cholesterol; UA, uric acid; $\gamma$-GTP, $\gamma$-glutamyl transpeptidase; Cre, creatinine; CRP, C-reactive protein; SAA-LDL, serum amyloid A-LDL; AT-LDL, $\alpha \mathrm{I}$-antitrypsin-LDL; FEV \%, percent forced expiratory volume in I second; $\mathrm{SD}$, standard deviation.

CRP, SAA-LDL, and percent forced expiratory volume in 1 second. The patients in the placebo group had a significantly higher body mass index than those in the Theracurmin ${ }^{\circledR}$ group $(P=0.046)$. The Theracurmin ${ }^{\circledR}$ group had significantly higher levels of AT-LDL than did the placebo group $(P=0.037)$.

The percent changes in parameters between the baseline and after 6 months of Theracurmin ${ }^{\circledR}$ or placebo administration are listed in Table 2. There were no significant differences in the percent changes in CRP and SAA-LDL (primary end points) between the groups. However, the percent change in all primary end points increased in the placebo group but decreased in the Theracurmin ${ }^{\circledR}$ group. The levels of AT-LDL, which is oxidatively modified LDL, were also a primary end point. The percent change in AT-LDL was significantly lower in the Theracurmin ${ }^{\circledR}$ group compared with that in the placebo group $(P=0.020)$.

\section{Discussion}

AT-LDL is closely related to arteriosclerosis. In the current trial, curcumin significantly decreased the blood levels of AT-LDL in patients with mild COPD.

Systemic inflammation in COPD is known to be associated with a risk of cardiovascular diseases. ${ }^{25} \mathrm{COPD}$ itself is a risk factor for arteriosclerosis, and the systemic effects of COPD are known to cause various comorbidities, such as a 
Table 2 Percent changes in parameters in each group

\begin{tabular}{llllll}
\hline Parameters & $\mathbf{n}$ & Placebo & $\mathbf{n}$ & Theracurmin $^{\circledR}$ & P-value \\
\hline$\Delta$ BMI & 17 & $-0.7 \pm 1.6$ & 22 & $0.9 \pm 2.1$ & 0.019 \\
$\Delta$ SBP & 17 & $1.4 \pm 17.6$ & 22 & $-1.3 \pm 15.9$ & 0.618 \\
$\Delta$ DBP & 17 & $2.9 \pm 13.4$ & 22 & $3.5 \pm 19.2$ & 0.904 \\
$\Delta$ HbAlc & 17 & $0.0 \pm 2.6$ & 22 & $0.4 \pm 3.0$ & 0.631 \\
$\Delta$ BS & 16 & $14.5 \pm 37.5$ & 21 & $5.8 \pm 25.7$ & 0.407 \\
$\Delta$ TG & 17 & $14.5 \pm 55.3$ & 22 & $9.2 \pm 44.0$ & 0.743 \\
$\Delta$ LDL-C & 17 & $11.4 \pm 26.8$ & 22 & $4.6 \pm 21.0$ & 0.383 \\
$\Delta$ HDL-C & 17 & $2.0 \pm 16.3$ & 22 & $-2.8 \pm 13.0$ & 0.317 \\
$\Delta$ UA & 16 & $2.3 \pm 18.6$ & 22 & $2.4 \pm 9.2$ & 0.970 \\
$\Delta \gamma-G T P$ & 17 & $-1.2 \pm 21.3$ & 22 & $-5.7 \pm 36.5$ & 0.654 \\
$\Delta$ Cre & 16 & $1.4 \pm 8.2$ & 22 & $2.9 \pm 10.0$ & 0.611 \\
$\Delta$ CRP & 16 & $11.1 \pm 98.3$ & 22 & $-12.5 \pm 51.9$ & 0.344 \\
$\Delta$ SAA-LDL & 15 & $10.8 \pm 47.4$ & 21 & $-2.0 \pm 41.9$ & 0.400 \\
$\Delta$ AT-LDL & 15 & $14.8 \pm 23.8$ & 21 & $-1.6 \pm 16.7$ & 0.020 \\
$\Delta$ FEV $\%$ & 16 & $-3.6 \pm 6.0$ & 21 & $-1.9 \pm 6.1$ & 0.411 \\
\hline Notes $D$ & & &
\end{tabular}

Notes: Data presented as mean \pm standard deviation unless stated otherwise. The percent change expresses the difference of baseline and after 6 months as a percentage of baseline. The percent change $=([$ after 6 months value - baseline value)/baseline value) $\times 100$.

Abbreviations: BMI, body mass index; SBP, systolic blood pressure; DBP, diastolic blood pressure; HbAlc, hemoglobin Alc; BS, blood sugar; TG, triglyceride; LDL-C, low-density lipoprotein-cholesterol; HDL-C, high-density lipoproteincholesterol; UA, uric acid; $\gamma$-GTP, $\gamma$-glutamyl transpeptidase; Cre, creatinine; CRP, C-reactive protein; SAA-LDL, serum amyloid A-LDL; AT-LDL, $\alpha$ I-antitrypsin$\mathrm{LDL} ; \mathrm{FEV}, \%$, percent forced expiratory volume in I second.

1.5- to 2-fold increase in the risk of ischemic heart disease. ${ }^{26}$ Currently, because there is no definitive treatment for COPD and no treatment to restore the lung function, bronchodilators and steroids are used to treat COPD by improving respiratory function. However, some of these medications, such as $\beta_{2}$-agonists, worsen comorbidities such as myocardial infarction that are caused by the systemic effects of COPD. The $\beta_{2}$-agonists are used as bronchodilators to treat patients with asthma or COPD and are thought to cause fewer adverse reactions in the cardiovascular system than $\beta_{1}$-agonists; however, $\beta_{2}$-agonists are reported to increase heart rate and lower potassium levels, potentially increasing the cardiovascular risk for patients with asthma or COPD. ${ }^{27}$ A study examining steroids and the occurrence of cardiovascular events reported that steroids significantly increased the risk of a cardiovascular event. ${ }^{28}$ Curcumin was used in the current trial, and no studies have reported serious adverse reactions to curcumin. Curcumin is a highly safe natural herbal product, and a study has suggested that curcumin may be effective in treating numerous disorders, such as heart disease, malignancies, lifestyle-related diseases, neurological disorders, inflammatory diseases, and infections. ${ }^{19-22}$

A comparison of AT-LDL levels in smokers and nonsmokers indicated that AT-LDL levels are significantly elevated in smokers. ${ }^{29}$ AT-LDL is an oxidatively modified
LDL, and AT-LDL levels quickly drop as a result of smoking cessation, which suggests that AT-LDL promotes atherosclerosis and is closely related to smoking. Based on these findings, it may be a useful marker to assess cardiovascular risk. Given that AT-LDL levels decreased significantly as a result of taking Theracurmin ${ }^{\circledR}$, curcumin may prevent the onset of arteriosclerosis in COPD and consequently reduce the cardiovascular risk. The baseline AT-LDL levels were significantly higher in the Theracur$\min ^{\circledR}$ group, but levels of AT-LDL and other inflammatory markers and oxidative stress markers, such as CRP and SAA-LDL, tended to decrease in the Theracurmin ${ }^{\circledR}$ group, suggesting that the inflammation in COPD is likely to be inhibited by Theracurmin ${ }^{\circledR}$.

The mechanism by which curcumin inhibits oxidized LDL is not clear. Many studies have reported that curcumin has anti-inflammatory and antioxidant activities. ${ }^{30-32} \mathrm{TNF}-\alpha$, cyclooxygenase-2 (COX-2), STAT, cyclin D1, and NF- $\kappa \mathrm{B}$ are related to inflammation, and curcumin displays antiinflammatory action by inhibiting TNF- $\alpha$, COX-2, STAT, cyclin D1, and NF- $\mathrm{BB}$ signaling. The chemical formula for curcumin is 1,7-bis-(4-hydroxy-3-methoxyphenyl)hepta-1,6-diene-3,5-dione. Curcumin displays antioxidant activity because the $\mathrm{CH}_{2}$ located in the center of the molecule and hydroxyl groups in the benzene rings eliminate reactive oxygen species. ${ }^{30,33}$ These actions of curcumin may be related to the mechanism by which curcumin inhibits oxidized LDL.

A retrospective cohort study of 854 patients with COPD examined differences in the mortality rate depending on whether patients were treated with statins. ${ }^{34}$ In this study, the hazard ratio for death of patients taking statins was 0.57 (95\% confidence interval $0.38-0.87$ ) compared with patients not taking statins. The study reported that treatment with statins was associated with an improvement in the survival rate after the exacerbation of COPD. A cohort study of 11,212 patients reported that angiotensin-converting enzyme inhibitors and angiotensin II receptor blockers improved the prognosis for patients with COPD. ${ }^{35}$ Cardiovascular events are complications of COPD, and treatment must inhibit cardiovascular events to improve the prognosis for patients with COPD.

The current trial used Theracurmin ${ }^{\circledR}$, a highly absorbable curcumin preparation. We examined blood inflammatory markers and respiratory function in patients with mild COPD over 6 months. Compared with the placebo, Theracurmin $^{\circledR}$ significantly decreased the blood levels of the inflammatory marker AT-LDL and tended to decrease (albeit not significantly) levels of CRP and SAA-LDL. 
However, as a limitation, this trial had a small sample and was conducted over a short period of time (6 months). A long-term study with cardiovascular events as a primary end point and numerous patients with COPD will probably clarify the relationship between curcumin and inflammation and cardiovascular events in COPD. If a natural product that is inexpensive and safe can be used to prevent and treat cardiovascular disease, then such a treatment could greatly benefit public health and welfare and reduce medical expenses in the process.

\section{Conclusion}

In patients with COPD and inflammatory disease, the current trial indicated that Theracurmin ${ }^{\circledR}$ might reduce levels of AT-LDL, a complex that promotes arteriosclerosis. COPD is an inflammatory disease, and curcumin may help to prevent ischemic disorders (eg, myocardial infarction), which are a comorbidity of COPD. This study suggests that curcumin could help in preventing the development of vascular events in patients with COPD.

\section{Acknowledgments}

The current trial was conducted with a research grant from the National Hospital Organization. The authors wish to sincerely thank the subjects for their participation in this trial.

\section{Disclosure}

Theravalues is a company that develops and markets Theracurmin ${ }^{\circledR}$. An agreement on joint research in relation to this trial was conducted between Theravalues and the Kyoto Medical Center. The tested samples of Theracurmin ${ }^{\circledR}$ and the placebo were donated by Theravalues. The authors report no other conflicts of interest in this work.

\section{References}

1. Tan WS, Peh HY, Liao W, et al. Cigarette smoke-induced lung disease predisposes to more severe infection with nontypeable haemophilus influenzae: protective effects of andrographolide. J Nat Prod. 2016;79(5): $1308-1315$

2. Su B, Liu T, Fan H, et al. Inflammatory markers and the risk of chronic obstructive pulmonary disease: a systematic review and meta-analysis. PLoS One. 2016;11(4):e0150586.

3. Barnes PJ, Celli BR. Systemic manifestations and comorbidities of COPD. Eur Respir J. 2009;33(5):1165-1185.

4. Owens RL, Malhotra A. Sleep-disordered breathing and COPD: the overlap syndrome. Respir Care. 2010;55:1333-1344.

5. Gan WQ, Man SF, Senthilselvan A, Sin DD. Association between chronic obstructive pulmonary disease and systemic inflammation: a systematic review and a meta-analysis. Thorax. 2004;59(7):574-580.

6. Agusti A, Soriano JB. COPD as a systemic disease. COPD. 2008;5(2): 133-138.

7. Yan ZQ, Hansson GK. Innate immunity, macrophage activation, and atherosclerosis. Immunol Rev. 2007;219:187-203.
8. Frostegård J, Ulfgren AK, Nyberg P, et al. Cytokine expression in advanced human atherosclerotic plaques: dominance of pro-inflammatory (Th1) and macrophage-stimulating cytokines. Atherosclerosis. 1999; 145(1):33-43.

9. Sin DD, Anthonisen NR, Soriano JB, Agusti AG. Mortality in COPD: role of comorbidities. Eur Respir J. 2006;28(6):1245-1257.

10. Mannino DM, Doherty DE, Sonia Buist A. Global Initiative on Obstructive Lung Disease (GOLD) classification of lung disease and mortality: findings from the Atherosclerosis Risk in Communities (ARIC) study. Respir Med. 2006;100(1):115-122.

11. Tashkin DP, Celli B, Senn S. A 4-year trial of tiotropium in chronic obstructive pulmonary disease. $N$ Engl J Med. 2008;359(15):1543-1554.

12. Celli B, Decramer M, Leimer I, Vogel U, Kesten S, Tashkin DP. Cardiovascular safety of tiotropium in patients with COPD. Chest. 2010;137(1):20-30.

13. Iso $\mathrm{H}$, Noda $\mathrm{H}$, Ikeda $\mathrm{A}$, et al. The impact of C-reactive protein on risk of stroke, stroke subtypes, and ischemic heart disease in middle-aged Japanese: the Japan public health center-based study. J Atheroscler Thromb. 2012;19(8):756-766.

14. Ridker PM, Cushman M, Stampfer MJ, Tracy RP, Hennekens CH. Plasma concentration of C-reactive protein and risk of developing peripheral vascular disease. Circulation. 1998;97(5):425-428.

15. Ridker PM, Cushman M, Stampfer MJ, Tracy RP, Hennekens CH. Inflammation, aspirin, and the risk of cardiovascular disease in apparently healthy men. $N$ Engl J Med. 1997;336(14):973-979.

16. Mashiba S, Wada $\mathrm{Y}$, Takeya $\mathrm{M}$, et al. In vivo complex formation of oxidized alpha (1)-antitrypsin and LDL. Arterioscler Thromb Vasc Biol. 2001;21(11):1801-1808.

17. Komiyama M, Wada $\mathrm{H}$, Ura $\mathrm{S}$, et al. The effects of weight gain after smoking cessation on atherogenic $\alpha 1$-antitrypsin-low-density lipoprotein. Heart Vessels. 2015;30(6):734-739.

18. Ogasawara K, Mashiba S, Wada Y, et al. A serum amyloid A and LDL complex as a new prognostic marker in stable coronary artery disease. Atherosclerosis. 2004;174(2):349-356.

19. Menon VP, Sudheer AR. Antioxidant and anti-inflammatory properties of curcumin. Adv Exp Med Biol. 2007;595:105-125.

20. Zhou H, Beevers CS, Huang S. The targets of curcumin. Curr Drug Targets. 2011;12(3):332-347.

21. Shimatsu A, Kakeya H, Imaizumi A, Morimoto T, Kanai M, Maeda S. Clinical application of "curcumin", a multi-functional substance. Anti-Aging Med. 2012;9:43-51.

22. Morimoto T, Sunagawa Y, Kawamura T, et al. The dietary compound curcumin inhibits p300 histone acetyltransferase activity and prevents heart failure in rats. J Clin Invest. 2008;118(3):868-878.

23. Sasaki H, Sunagawa $Y$, Takahashi K, et al. Innovative preparation of curcumin for improved oral bioavailability. Biol Pharm Bull. 2011; 34(5):660-665.

24. Fan Z, Yao J, Li Y, Hu X, Shao H, Tian X. Anti-inflammatory and antioxidant effects of curcumin on acute lung injury in a rodent model of intestinal ischemia reperfusion by inhibiting the pathway of NF-Kb. Int J Clin Exp Pathol. 2015;8(4):3451-3459.

25. Engström G, Lind P, Hedblad B, et al. Lung function and cardiovascular risk: relationship with inflammation-sensitive plasma proteins. Circulation. 2002;106(20):2555-2560.

26. Curkendall SM, DeLuise C, Jones JK, et al. Cardiovascular disease in patients with chronic obstructive pulmonary disease, Saskatchewan Canada cardiovascular disease in COPD patients. Ann Epidemiol. 2006;16(1):63-70.

27. Salpeter SR, Ormiston TM, Salpeter EE. Cardiovascular effects of betaagonists in patients with asthma and COPD: a meta-analysis. Chest. 2004;125(6):2309-2321.

28. Souverein PC, Berard A, Van Staa TP, et al. Use of oral glucocorticoids and risk of cardiovascular and cerebrovascular disease in a population based case-control study. Heart. 2004;90(8):859-865.

29. Wada H, Ura S, Satoh-Asahara N, et al. $\alpha 1$-Antitrypsin low-densitylipoprotein serves as a marker of smoking-specific oxidative stress. J Atheroscler Thromb. 2012;19(1):47-58. 
30. Ghosh S, Banerjee S, Sil PC. The beneficial role of curcumin on inflammation, diabetes and neurodegenerative disease: a recent update. Food Chem Toxicol. 2015;83:111-124.

31. He Y, Yue Y, Zheng X, Zhang K, Chen S, Du Z. Curcumin, inflammation, and chronic diseases: how are they linked? Molecules. 2015; 20(5):9183-9213.

32. Meng B, Li J, Cao H. Antioxidant and antiinflammatory activities of curcumin on diabetes mellitus and its complications. Curr Pharm Des. 2013;19(11):2101-2113.
33. Joe B, Lokesh BR. Role of capsaicin, curcumin and dietary n-3 fatty acids in lowering the generation of reactive oxygen species in rat peritoneal macrophages. Biochim Biophys Acta. 1994;1224(2):255-263.

34. Søyseth V, Brekke PH, Smith P, Omland T. Statin use is associated with reduced mortality in COPD. Eur Respir J. 2007;29(2):279-283.

35. Mortensen EM, Copeland LA, Pugh MJ, et al. Impact of statins and ACE inhibitors on mortality after COPD exacerbations. Respir Res. $2009 ; 10: 45$.

\section{Publish your work in this journal}

The International Journal of COPD is an international, peer-reviewed journal of therapeutics and pharmacology focusing on concise rapid reporting of clinical studies and reviews in COPD. Special focus is given to the pathophysiological processes underlying the disease, intervention programs, patient focused education, and self management protocols.

\section{Dovepress}

This journal is indexed on PubMed Central, MedLine and CAS. The manuscript management system is completely online and includes a very quick and fair peer-review system, which is all easy to use. Visit $\mathrm{http}: / / \mathrm{www}$.dovepress.com/testimonials.php to read real quotes from published authors. 